\title{
The contemporary role on surgery in the management of renal masses
}

\author{
Nils Kroeger • Arie S. Belldegrun • Allan J. Pantuck
}

Published online: 10 April 2014

(C) Springer-Verlag Berlin Heidelberg 2014

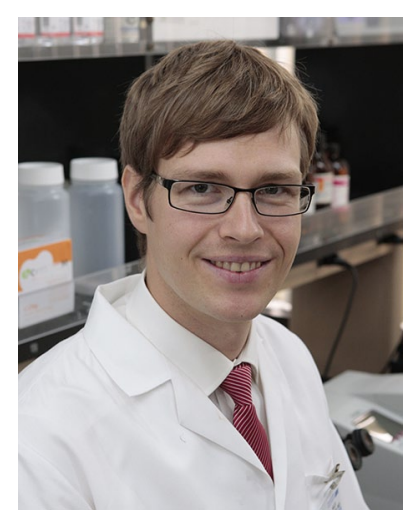

Nils Kroeger

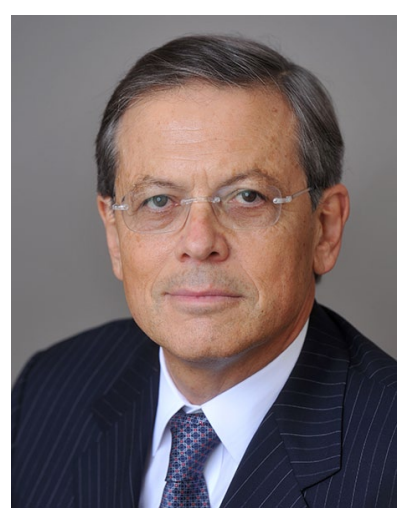

Arie S. Belldegrun

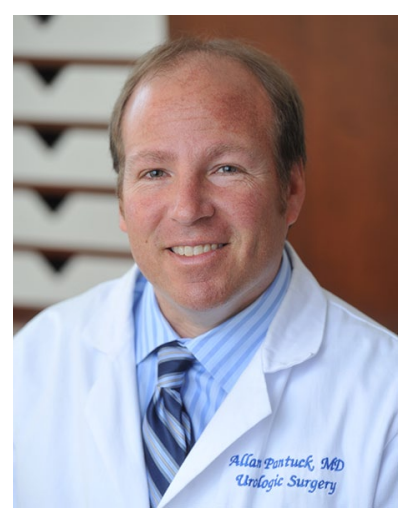

Allan J. Pantuck
Approaches to the surgical treatment of renal cell carcinoma (RCC) are rapidly evolving. The foundations for what became the generally accepted principles underlying the surgical management of RCC for the latter third of the twentieth century were first annunciated in 1969 by Robson et al. [1] in his classic paper describing the radical nephrectomy. Since that era, when the majority of renal tumors were large and already locally advanced at the time of diagnosis, much has changed in our understanding of the basic biology of kidney

\section{N. Kroeger}

Department of Urology, University Medicine Greifswald,

Greifswald, Germany

e-mail: kroegern@uni-greifswald.de

\author{
A. S. Belldegrun · A. J. Pantuck $(\bowtie)$ \\ Institute of Urologic Oncology, David Geffen School of Medicine \\ at UCLA, Los Angeles, CA, USA \\ e-mail: apantuck@mednet.ucla.edu
}

A. S. Belldegrun

e-mail: abelldegrun@mednet.ucla.edu cancer with the recognition that it represents not a single entity but rather a family of tumors having a wide spectrum of behaviors and risks, while advances and increased utilization of abdominal imaging and clinical staging have led to the increased detection of incidental, lower stage, organ-confined, often indolent tumors more amendable to expanded surgical options. New research results have challenged even the concept of surgery for all RCCs itself, advocating the initial deferment of active treatment in elderly patients and in those with significant comorbidities [2]. Surgical techniques themselves have evolved to include routine use of nephron sparing techniques even in the presence of a normal contralateral kidney, and both radical and partial nephrectomy have themselves further evolved to include laparoscopic and robotic-assisted minimally invasive approaches, while advances in the development of energy ablative technology such as cryotherapy and radiofrequency ablation that can be delivered percutaneously have advanced to make possible new methods of managing renal tumors in situ. Thus, the surgical management of RCC has changed dramatically 
in the last 20 years, predicated on these major advancements in renal imaging and in surgical equipment and techniques. In the current special issue of the World Journal of Urology, world leading experts present the current state of the art in the surgical management of renal masses.

Despite the trends mentioned above, one-third of RCC patients still present with locally advanced or metastasized tumor stages [3]. Targeted therapies have internationally been recognized as the standard of care therapies for metastatic RCC (mRCC) [4], yet it is currently uncertain whether mRCC patients require a cytoreductive nephrectomy as an adjunct to the use of these targeted therapies, and if it is indeed needed, the optimal timing to perform surgery is currently unknown. In the management of $\mathrm{mRCC}$, surgeons are often called upon to perform metastatectomies. However, the overall efficacy of metastatectomy in different metastatic sites is currently uncertain. Furthermore, advanced RCCs with invasion into the vena cava and lymphatic spread still challenge urological surgeons with unsolved problems.

Hereditary RCCs are a unique subgroup of RCC requiring frequently recurrent surgical interventions. Bratslavsky et al. discuss the special needs of surgical interventions in hereditary RCC. The question whether surgery is mandatory in every patient is discussed by Uzzo et al. Current controversies related to partial nephrectomy are discussed by Lane et al., while $\mathrm{Hu}$ et al. discuss challenges and controversies in different minimally invasive surgical techniques. Some patients select ablative rather than extirpative surgery. Alternative techniques that could be provided to these patients are discussed in the paper of Pantuck et al. locally advanced
RCC are a challenge for even experienced urological surgeons. While Shuch et al. discuss the clinical management of RCC with vena cava infiltration, Blute et al. give a comprehensive overview on the current knowledge of the role of lymphadenectomy in renal cancer. Additionally, two articles are dedicated to describe the contemporary role of surgery in mRCC: Margulis et al. discuss the role of cytoreductive surgery and the role of neoadjuvant therapy for mRCC, while Wood et al. provide the reader with current evidence supporting the use of metastasectomy.

We hope that this special issue of the World Journal of Urology will provide a comprehensive overview as well as new insights and perspectives in the surgical management of RCC.

\section{References}

1. Robson CJ, Churchill BM, Anderson W (1969) The results of radical nephrectomy for renal cell carcinoma. J Urol 101:297-301

2. Campbell SC, Novick AC, Belldegrun A, Blute ML, Chow GK, Derweesh IH, Faraday MM, Kaouk JH, Leveillee RJ, Matin SF, Russo P, Uzzo RG (2009) Guideline for management of the clinical T1 renal mass. J Urol 182:1271-1279

3. Birkhäuser F, Kroeger N, Pantuck A (2012) Etiology of RCC: incidence, demographics, and environmental factors. In: Rini B, Campbell S (eds) Renal cell carcinoma: clinical management, vol 1. Springer Science+Business Media, New York, pp 3-22

4. Patard JJ, Pignot G, Escudier B, Eisen T, Bex A, Sternberg C, Rini B, Roigas J, Choueiri T, Bukowski R, Motzer R, Kirkali Z, Mulders P, Bellmunt J (2011) ICUD-EAU international consultation on kidney cancer 2010: treatment of metastatic disease. Eur Urol 60:684-690 